\title{
GHSR Deficiency Suppresses Neointimal Formation in Injured Mouse Arteries
}

Jing Li, Man Zhang, Mo Wang, Zhipeng Wang, Yahan Liu, Weizhen Zhang, Nanping Wang

Institute of Cardiovascular Sciences, Peking University Health Science Center, Beijing 100191, China; The Advanced Institute for Medical Sciences, Dalian Medical University, Dalian, 116044, China

Please address correspondence to:

Nanping Wang, MD, Ph.D

Institute of Cardiovascular Sciences,

Peking University Health Science Center,

Beijing 100191, China

Phone: +86-10-82801446

Fax: +86-10-82801559

E-mail: npwang@hsc.pku.edu

This total word count of the manuscript is 4283 . 


\begin{abstract}
Growth hormone secretagogue receptor (GHSR) is involved in appetite regulation and energy homeostasis. In the present study, we examined the role of GHSR in neointimal formation following vascular injury. In the mouse model of femoral artery wire injury, we found that vessel intima-to-media ratio was significantly reduced in GHSR deficiency $\left(\mathrm{GHSR}^{-1-}\right)$ mice compared with that in wild-type mice. Immunohistochemical staining showed that the smooth muscle cell (SMCs) in the neointima were significantly decreased in the injured arteries of $\mathrm{GHSR}^{-/-}$mice which was associated with decreased SMC proliferation and migration. Furthermore, immunoblotting demonstrated that, in cultured rat aortic SMCs, small interfering RNA-mediated GHSR knockdown suppressed the activation of Akt and ERK1/2 signaling pathway. These findings suggested a novel role of GHSR in neointimal formation likely via promoting the proliferation and migration of SMCs involving Akt and ERK1/2 signaling. Therefore, GHSR may be a potential therapeutic target in restenosis and vascular remodeling.
\end{abstract}

KEY WORDS: growth hormone secretagogue receptor, neointimal formation, smooth muscle cell 


\section{Introduction}

Percutaneous coronary intervention (PCI) has been a widely used treatment for ischemic heart disease due to atherosclerosis. However, renarrowing of the treated arteries, known as restenosis still remains a great challenge in a long-term. The pathogeneses of restenosis following mechanical injury of endothelium involve a cascade of processes including platelet aggregation, inflammatory cell infiltration, and the release of growth factors and chemokiens, leading to the phenotypic changes, migration and proliferation of smooth muscle cells, and the synthesis and deposition of proteoglycan, and other extracellular matrix components, leading to neointimal hyperplasia, and vessel remodeling [1, 2].

Growth hormone secretagogue receptor (GHSR) is a member of G-protein-coupled receptor family [3]. GHSR is predominantly expressed in human pituitary, rhypothalamus and hippocampus [4]. GHSR is also expressed in peripheral tissues including lungs, liver, kidney, and adrenal gland. In cardiovascular system, it is found in vascular smooth muscle cells (SMCs) and endothelial cells [5]. Ghrelin, the endogenous ligand of GHSR, is a peptide hormone with 28 amino acids mainly secreted by the gastrointestinal system [6]. Two subtypes of GHSR, GHSR-1a and GHSR-1b, have been identified. GHSR-1a is considered as the active subtype. Whereas GHSR-1b binds neither ghrelin nor synthetic ligands GHSs [7].

GHSR plays crucial roles in promoting growth hormone secretion, regulation of food intake, and other physiological processes such as insulin secretion, glucose and lipid metabolism [8]. In addition, GHSR has been shown to exert beneficial effects on cardiovascular system by improving heart function, inhibiting ventricular remodeling, and attenuating ischemiareperfusion (I/R) injury [9-11]. More studies revealed that GHSR is involved in the cellular processes such as proliferation, migration and apoptosis [12-15]. In addition, its ligand ghrelin inhibits the expression of proinflammatory cytokines such as IL-1 $\beta$, IL-6, IL-8, TNF- 
$\alpha$ and MCP-1 $[16,17]$. These observations imply that GHSR may play an important role in the vascular homeostasis. However, the function and mechanism of GHSR in restenosis after vascular injury remain to be identified.

In the present study, we examined the role of GHSR in neointimal formation using the GHSR knockout mice. Importantly, our data demonstrated for the first time that GHSR deficiency significantly suppressed neointimal formation in vivo. And we found that knockdown GHSR attenuated SMC proliferation and migration through inhibiting phosphorylation of Akt and ERK1/2. 


\section{Methods}

\section{Reagents}

Antibodies against $\alpha$-smooth muscle actin ( $\alpha$-SMA) and F4/80 were from Abcam (Cambridge, MA, USA). Antibodies against Akt, phosphor-Akt, extracellular signal-regulated kinase 1/2 (ERK1/2), and phosphor-ERK1/2 were from Cell Signaling Technology (Boston, Ma, USA). Antibody against GHSR was from Santa Cruz Biotechnology (Santa Cruz, CA, USA). Antibody against BrdU was from Zhongshan Golden Bridge (Beijing, China). 5-bromo-2'deoxyuridine (BrdU) and PDGF-BB were from Sigma-Aldrich (St. Louis, MO, USA). Ghrelin was purchased from TOCRIS (Avonbridge, Bristol, UK.).

\section{Experimental Animals and Femoral Artery Injury in Mice}

The animal study was approved by the Animal Experimentation Committee of Peking University Health Science Center. Male mice (12 to 16 week-old) were used in a C57BL/6J background. GHSR deficient $\left(\mathrm{GHSR}^{-/}\right)$mice were generated as previously described [18]. Wire-mediated vascular injury was induced in the femoral arteries of $\mathrm{GHSR}^{-/-}$mice and ageand gender-matched wild-typed $\left(\mathrm{GHSR}^{+/+}\right)$mice by an angioplasty guide wire as described previously [19]. Briefly, mice were anesthetized with an intraperitoneal injection of pentobarbital sodium $(60 \mathrm{mg} / \mathrm{kg})$. Right femoral arteries were exposed and inserted into a guide wire $0.35 \mathrm{~mm}$ in diameter for $1 \mathrm{~min}$ under a surgical microscope. After removing the wire, the arteriotomy site was ligated and skin incision was closed with silk suture. The uninjured left femoral arteries served as negative controls. Animals were monitored as per usual after surgery.

\section{Tissue Preparation and Morphometry}


Injured arteries were prepared and measured as described previously [20]. Mice were euthanized with intraperitoneal injection of pentobarbital sodium on the 14 and 28 days after arterial injury. The vessels were perfused with PBS and fixed with $4 \%$ paraformaldehyde through the left ventricle of the heart. The hindlimbs were isolated, fixed in $4 \%$ paraformaldehyde overnight, decalcified, embedded in paraffin wax and cut into 5- $\mu \mathrm{m}$ sections for further analysis. Six sections per femoral artery were stained by hematoxylin and eosin, and sections with maximal neointima were evaluated. The intima and media areas were measured by computerized morphometry with Image $\mathbf{J}$ software. Neointimal hyperplasia was defined as the formation of the layer within the inner elastic lamina. Medial areas were calculated as the area encircled by the external elastic lamina subtracting the area encircled by the inner elastic lamina. The intima-to-media ratio represents the intimal area divided by the medial area.

\section{Immunohistochemistry}

Femoral artery sections were dewaxed, rehydrated and endogenous peroxidase was denatured with $3 \% \mathrm{H}_{2} \mathrm{O}_{2}$. Then the cross sections were treated to retrieve the antigen in EDTA (pH 8.0) at $92^{\circ} \mathrm{C}$ for $10 \mathrm{~min}$. After blocking with normal goat serum, sections were incubated with the primary antibodies against $\alpha$-SMA and F4/80 followed by incubation with horseradish peroxidase-conjugated secondary antibodies. After washing with PBS, sections underwent 3,3'-diaminobenzidine (DAB) chromogen substrate and hematoxylin counterstaining. Images were photographed with Leica DM 3000 system. The numbers of nuclei that were stained by an $\alpha$-SMA-positive cytoplasm were counted at a magnification of $\times 400$ in 6 independent sections from each mouse [21].

In vivo bromodeoxyuridine (BrdU) labeling was performed to detect the vascular cell replication in wire-injured arteries as described previously [20]. Mice were intraperitoneally 
injected with BrdU $(30 \mathrm{mg} / \mathrm{kg})$ at 8 -hour intervals 3 times before mice were killed. Parrafin sections of arterial segments were denatured with $1.5 \mathrm{~N} \mathrm{HCl}$, neutralized with $0.1 \mathrm{M} \mathrm{Na}_{2} \mathrm{~B}_{4} \mathrm{O}_{7}$ (pH 8.5), incubated with anti-BrdU antibody and detected with HRP-conjugated antibody.

\section{Cell Culture and RNA Interference}

SMCs were isolated and cultured as described previously [22]. Briefly, male Sprague-Dawley rats (150 to $180 \mathrm{~g})$ were anesthetized and thoracic aortas were quickly isolated and dissected. Endothelia and adventitia were removed. Aortas were chopped into pieces and cultured in DMEM containing $20 \%$ fetal bovine serum (FBS), 10U/mL penicillin, and $10 \mathrm{U} / \mathrm{mL}$ streptomycin at $37^{\circ} \mathrm{C}$ in a $5 \% \mathrm{CO}_{2}$ humidified incubator. Cells at passages 3 to 7 were used.

The double-stranded siRNA $(80 \mathrm{nmol} / \mathrm{L})$ targeting rat GHSR mRNA (5'UCUGCAAACUCUUCCAGUUTT-3') or scramble control were transfected in Opti-MEM and using Lipofectamine2000 ${ }^{\mathrm{TM}}$ (Invitrogen, Carlsbad, CA, USA).

\section{Quantitative RT-PCR}

Total RNA was isolated with TRIzol reagent (Life Technologies) and reverse transcribed by using M-MLV transcriptase and random primers. qPCR was performed on Mx3000 Multiplex qPCR System (Agilent, Santa Clara, CA) with the GoTaq® qPCR Master Mix (Promega, WI, USA) and specific primers for GHSR and $\beta$-actin as an internal control. The primers for rat GHSR were 5'-CACCTACGCCACGGTCCTCA-3' (sense), and 5'AGCTTCACGCGGCCCTTA-3' (antisense), and the primers for rat $\beta$-actin were 5'ATCGTGGGCCGCCCTAGGCACC-3' CTCTTTAATGTCACGCACGATTTC-3' (antisense).

\section{Western Blotting}


SMC proteins were extracted with RIPA buffer. Equal amounts of proteins were separated on $10 \%$ sodium dodecyl sulfate polyacrylamide gels electrophoresis (SDS-PAGE) and transferred onto polyvinylidene difluoride (PVDF) membranes. The membranes were blocked with $5 \%$ non-fat milk, incubated with primary antibodies against GHSR, p-Akt, Akt, p-ERK, ERK and GAPDH overnight and reacted with secondary antibodies .

\section{Cell Proliferation Assay}

Cell proliferation was evaluated by cell counting as described previously [23]. After transfected with siRNA for 12 hours, SMCs were trypsinized and 5000 cells were transferred to each well of a 96-well plate. SMCs synchronized by 24-hours serum starvation were stimulated with ghrelin (100nM) for 24 hours and incubated with Cell Counting Kit-8 (CCK8) reagent for 4 hours. The OD (optical density) value at $450 \mathrm{~nm}$ was read with a microplate reader.

\section{Transwell Migration Assay}

SMCs were plated in a $35-\mathrm{mm}^{2}$ dish and transfected with siRNA at $70 \%$ confluence. Cells were then transferred to Transwell plates with $8-\mu \mathrm{m}$ pores polycarbonate membrane filters (Corning, Corning, NY) to investigate of SMC migration as described [20]. SMCs were cultured in DMEM without FBS and the lower chamber contained PDGF-BB (5ng/mL) as a stimulation. After 24 hours, the cells were fixed with $4 \%$ paraformaldehyde and stained with crystal violet. The cells on the upper surface were then wiped off gently by a cotton bud and the cells on the underside (migrated cells) were quantified under light microscopy in 4 independent duplicated experiments.

\section{Statistical Analysis}


All results were expressed as the mean \pm SEM. Results were analyzed with Student's t-test. $\mathrm{P}<0.05$ was considered statistically significant. 


\section{Results}

\section{GHSR Deficiency Inhibits Neointimal Formation after Vascular Injury}

To determine the role of the GHSR in intimal hyperplasia in vivo, we evaluated neointimal formation in $\mathrm{GHSR}^{-/-}$mice at 14 and 28 days after wire injury. Compared with wide-type (WT) mice, neointimal formation was significantly reduced in $\mathrm{GHSR}^{-/-}$mice (Figure 1A). Quantitative morphometry exhibited remarkable decrease in the neointimal area and intimato-media (I/M) ratio in $\mathrm{GHSR}^{-/-}$compared with that in WT mice (Figure 1B and 1D). In contrast, the luminal areas were significantly increased in $\mathrm{GHSR}^{-/-}$mice (Figure 1C). Of note, there was no significant difference between of two groups in term of the media area (Figure 1E).

\section{GHSR Deficiency Suppresses SMCs Numbers in Vivo}

To characterize the cell composition of the neointima, sections of injured arteries from WT and $\mathrm{GHSR}^{-/-}$mice were stained with the markers for VSMCs ( $\alpha$-SMA) and macrophages (F4/80). The staining showed that cells present in neointima were predominantly SMCs with few macrophages in both WT and $\mathrm{GHSR}^{-/-}$mice (Figure 2A). The number of SMCs was significantly decreased in the injured arteries of $\mathrm{GHSR}^{-/-}$mice (Figure 2B). Consistent with the SMCs numbers, BrdU incorporation assay showed that BrdU-positive cell numbers was markedly reduced in $\mathrm{GHSR}^{-/-}$than WT mice in the intima at 8 days after vascular injury (Figure 2C and 2D).

\section{Knockdown GHSR Represses SMCs Proliferation and Migration in Vitro}

To determine the regulation of GHSR in SMCs proliferation and migration, the rat aortic SMCs were transfected with siRNA. Gene expression and protein level of GHSR were specifically knockdown by siRNA treatment (Figure 3A and 3B). 
Because GHSR ligand ghrelin has proliferative effect in multiple types of cells [13]. We investigated the function of GHSR deficiency in SMCs proliferation induced by ghrelin. After transfected with siRNA, SMCs were stimulated with ghrelin. Treatment of GHSR siRNA decreased SMCs proliferation measured (Figure 3C). We evaluated the effect of GHSR on SMCs migration by stimulation with PDGF-BB. As shown with transwell assay, GHSR siRNA repressed the migration of SMCs in response to PDGF-BB (Figure 3D and 3E).

\section{Knockdown GHSR inhibited Akt and ERK1/2 Phosphorylation in SMCs}

PI3K/Akt and MAPK/ERK signaling pathways mediate cell proliferation and migration. In order to explore the role of GHSR in regulating SMC proliferation and migration, we observed the ghrelin-induced Akt and ERK1/2 phosphorylation at different times by transfecting with GHSR siRNA. The Akt and ERK1/2 pathways were activated by 15-min after ghrelin treatment, and maintained until $60 \mathrm{~min}$. However, Akt and ERK1/2 phosphorylation levels were inhibited after GHSR siRNA transfection (Figure 4). These results indicated that knockdown GHSR attenuated proliferation and migration of SMCs via inhibiting the activation of PI3K/Akt and MAPK/ERK signaling pathways. 


\section{Discussion}

In the present study, we initially demonstrated that GHSR deficiency significantly inhibited the neointimal formation and improved the restenosis in wire-injury femoral arteries. We also found that the proliferation and migration of SMCs was suppressed after knocking down the GHSR. Finally, the molecular mechanism investigation showed that GHSR knockdown attenuated the phosphorylation of Akt and ERK1/2 and activation of the signal pathways.

Previous studies suggested that GHSR is expressed in a wide range of tissues including vasculature. GHSR is detected in aorta, coronary, pulmonary, arcuate arteries and saphenous vein [24, 25]. In addition, GHSR is significantly up-regulated in both atherosclerotic coronary arteries and saphenous vein grafts with advanced intimal thickening, compared with normal vessels [24]. However, in low-density lipoprotein receptor-null $\left(\mathrm{LDLR}^{-/-}\right)$mice, GHSR deficiency did not affect high-fat, high-cholesterol western-type diet induced atherosclerosis [26]. Compared with $\mathrm{GHSR}^{+/+} / \mathrm{LDLR}^{-/-}$mice, $\mathrm{T}$ cells and macrophages are increased, while SMCs in atherosclerotic plaques were less in $\mathrm{GHSR}^{-/} / \mathrm{LDLR}^{-/-}$mice [27]. Here, we showed that neointimal formation was significantly suppressed in $\mathrm{GHSR}^{-/}$mice than WT mice after vascular injury. Our finding indicated an important role of GHSR in restenosis.

Ghrelin inhibits TNF- $\alpha$-induced NF- $\mathrm{BB}$ activation and monocyte adhesion, VCAM-1 expression [28, 29]. However, several inconsistent reports showed that ghrelin treatment increased the expression of ICAM-1, and promoted NF- $\kappa \mathrm{B}$ activation $[30,31]$. The recent study also points out that these is a significantly reduced pro-inflammatory cytokines in LPSstimulated macrophages in vitro from $\mathrm{GHSR}^{-/-}$mice than WT mice [32]. Ghrelin inhibited the proliferation of SMCs probably mediated by GHSR [33]. Our study further clearly demonstrated that the effect of GHSR on restenosis development. In vivo, neointimal 
formation significantly decreased and restenosis was improved in wire-injury femoral arteries of GHSR deficiency than WT mice. In vitro, knockdown GHSR exhibited inhibition of SMCs migration and proliferation.

Ghrelin has been reported to promote cells proliferation, migration and to inhibit cell apoptosis, and the underlying mechanisms may be involved in GHSR-mediated activation of MAPK and PI3K/Akt signaling pathways. Meanwhile the effect is significantly extenuated by pretreatment of cells with a GHSR inhibitor ([D-Lys3]-GHRH-6), PI3K inhibitor (LY294002) or ERK1/2 inhibitor (PD98059) [13, 15, 34]. In addition to the signaling pathways described above, ghrelin also regulates the proliferation and differentiation in a wide variety of cell types ranging from 3T3-L1 adipocytes, human embryonic stem cells to HepG2 cells [35-37]. In the present study, we found that the knockdown GHSR suppressed Akt and ERK1/2 phosphorylation and the activation of signaling pathway in cultured SMCs.

Restenosis is a complex and progressive pathological process. We examined that whether GHSR can regulate the intimal hyperplasia and cellular response to vascular damage. Our data demonstrated that GHSR deficiency significantly attenuates the neointimal formation and effectively alleviates restenosis development after vascular injury. This inhibitory effect may be contributed to inhibiting the proliferation and migration of SMCs through suppressing phosphorylation of Akt and ERK1/2. This research provides a new mechanism and a possible therapeutic measurement in pathological conditions associated with restenosis and vascular remodeling.

\section{ACKNOWLEDGMENTS}


This work was supported by grants from the National Science Foundation of China (No. $31430045)$.

\section{DISCLOSURES}

No conflicts of interest, financial or otherwise, are declared by the author.

\section{AUTHOR CONTRIBUTIONS}

From the Institute of Cardiovascular Sciences, Peking University Health Science Center, Beijing 100191, China (J.L., M.Z., M.W., Z.W., Y.L., W.Z, N.W.), Advanced Institute for Medical Sciences, Dalian Medical University, Dalian, 116044, China (N.W.) 


\section{REFERENCES}

[1] M.S. Kim, L.S. Dean, In-stent restenosis, Cardiovascular therapeutics, 29 (2011) 190-198.

[2] M.A. Costa, D.I. Simon, Molecular basis of restenosis and drug-eluting stents, Circulation, 111 (2005) 2257-2273.

[3] A.D. Howard, S.D. Feighner, D.F. Cully, J.P. Arena, P.A. Liberator, C.I. Rosenblum, M. Hamelin, D.L. Hreniuk, O.C. Palyha, J. Anderson, P.S. Paress, C. Diaz, M. Chou, K.K. Liu, K.K. McKee, S.S. Pong, L.Y. Chaung, A. Elbrecht, M. Dashkevicz, R. Heavens, M. Rigby, D.J. Sirinathsinghji, D.C. Dean, D.G. Melillo, A.A. Patchett, R. Nargund, P.R. Griffin, J.A. DeMartino, S.K. Gupta, J.M. Schaeffer, R.G. Smith, L.H. Van der Ploeg, A receptor in pituitary and hypothalamus that functions in growth hormone release, Science, 273 (1996) 974-977.

[4] X.M. Guan, H. Yu, O.C. Palyha, K.K. McKee, S.D. Feighner, D.J. Sirinathsinghji, R.G. Smith, L.H. Van der Ploeg, A.D. Howard, Distribution of mRNA encoding the growth hormone secretagogue receptor in brain and peripheral tissues, Brain research. Molecular brain research, 48 (1997) 23-29.

[5] M. Papotti, C. Ghe, P. Cassoni, F. Catapano, R. Deghenghi, E. Ghigo, G. Muccioli, Growth hormone secretagogue binding sites in peripheral human tissues, The Journal of clinical endocrinology and metabolism, 85 (2000) 3803-3807.

[6] M. Kojima, H. Hosoda, Y. Date, M. Nakazato, H. Matsuo, K. Kangawa, Ghrelin is a growthhormone-releasing acylated peptide from stomach, Nature, 402 (1999) 656-660.

[7] R.G. Smith, L.H. Van der Ploeg, A.D. Howard, S.D. Feighner, K. Cheng, G.J. Hickey, M.J. Wyvratt, Jr., M.H. Fisher, R.P. Nargund, A.A. Patchett, Peptidomimetic regulation of growth hormone secretion, Endocrine reviews, 18 (1997) 621-645.

[8] A. Laviano, A. Molfino, S. Rianda, F. Rossi Fanelli, The growth hormone secretagogue receptor (Ghs-R), Current pharmaceutical design, 18 (2012) 4749-4754.

[9] X.B. Xu, J.J. Pang, J.M. Cao, C. Ni, R.K. Xu, X.Z. Peng, X.X. Yu, S. Guo, M.C. Chen, C. Chen, GH-releasing peptides improve cardiac dysfunction and cachexia and suppress stress-related hormones and cardiomyocyte apoptosis in rats with heart failure, American journal of physiology. Heart and circulatory physiology, 289 (2005) H1643-1651.

[10] G.G. Zhang, X. Teng, Y. Liu, Y. Cai, Y.B. Zhou, X.H. Duan, J.Q. Song, Y. Shi, C.S. Tang, X.H. Yin, Y.F. Qi, Inhibition of endoplasm reticulum stress by ghrelin protects against ischemia/reperfusion injury in rat heart, Peptides, 30 (2009) 1109-1116.

[11] N. Nagaya, M. Uematsu, M. Kojima, Y. Ikeda, F. Yoshihara, W. Shimizu, H. Hosoda, Y. Hirota, H. Ishida, H. Mori, K. Kangawa, Chronic administration of ghrelin improves left ventricular dysfunction and attenuates development of cardiac cachexia in rats with heart failure, Circulation, 104 (2001) 1430-1435.

[12] F. Rossi, A. Castelli, M.J. Bianco, C. Bertone, M. Brama, V. Santiemma, Ghrelin inhibits contraction and proliferation of human aortic smooth muscle cells by cAMP/PKA pathway activation, Atherosclerosis, 203 (2009) 97-104.

[13] F. Rossi, A. Castelli, M.J. Bianco, C. Bertone, M. Brama, V. Santiemma, Ghrelin induces proliferation in human aortic endothelial cells via ERK1/2 and PI3K/Akt activation, Peptides, 29 (2008) 2046-2051.

[14] X. Chen, Q. Chen, L. Wang, G. Li, Ghrelin induces cell migration through GHSR1a-mediated PI3K/Akt/eNOS/NO signaling pathway in endothelial progenitor cells, Metabolism: clinical and experimental, 62 (2013) 743-752.

[15] Y. Xiang, Q. Li, M. Li, W. Wang, C. Cui, J. Zhang, Ghrelin inhibits AGEs-induced apoptosis in human endothelial cells involving ERK1/2 and PI3K/Akt pathways, Cell biochemistry and function, 29 (2011) 149-155.

[16] V.D. Dixit, E.M. Schaffer, R.S. Pyle, G.D. Collins, S.K. Sakthivel, R. Palaniappan, J.W. Lillard, Jr., D.D. Taub, Ghrelin inhibits leptin- and activation-induced proinflammatory cytokine expression by human monocytes and T cells, The Journal of clinical investigation, 114 (2004) 57-66.

[17] B. Deng, F. Fang, T. Yang, Z. Yu, B. Zhang, X. Xie, Ghrelin inhibits AngII -induced expression of TNF-alpha, IL-8, MCP-1 in human umbilical vein endothelial cells, International journal of clinical and experimental medicine, 8 (2015) 579-588. 
[18] Y. Qin, Z. Li, Z. Wang, Y. Li, J. Zhao, M. Mulholland, W. Zhang, Ghrelin contributes to protection of hepatocellular injury induced by ischaemia/reperfusion, Liver international : official journal of the International Association for the Study of the Liver, 34 (2014) 567-575.

[19] M. Sata, Y. Maejima, F. Adachi, K. Fukino, A. Saiura, S. Sugiura, T. Aoyagi, Y. Imai, H. Kurihara, K. Kimura, M. Omata, M. Makuuchi, Y. Hirata, R. Nagai, A mouse model of vascular injury that induces rapid onset of medial cell apoptosis followed by reproducible neointimal hyperplasia, Journal of molecular and cellular cardiology, 32 (2000) 2097-2104.

[20] S. Zhu, R. Xue, P. Zhao, F.L. Fan, X. Kong, S. Zheng, Q. Han, Y. Zhu, N. Wang, J. Yang, Y. Guan, Targeted disruption of the prostaglandin E2 E-prostanoid 2 receptor exacerbates vascular neointimal formation in mice, Arteriosclerosis, thrombosis, and vascular biology, 31 (2011) 17391747.

[21] R. Shibata, H. Kai, Y. Seki, S. Kato, M. Morimatsu, K. Kaibuchi, T. Imaizumi, Role of Rhoassociated kinase in neointima formation after vascular injury, Circulation, 103 (2001) 284-289.

[22] S. Jovinge, A. Hultgardh-Nilsson, J. Regnstrom, J. Nilsson, Tumor necrosis factor-alpha activates smooth muscle cell migration in culture and is expressed in the balloon-injured rat aorta, Arteriosclerosis, thrombosis, and vascular biology, 17 (1997) 490-497.

[23] T. Kessler, L. Zhang, Z. Liu, X. Yin, Y. Huang, Y. Wang, Y. Fu, M. Mayr, Q. Ge, Q. Xu, Y. Zhu, X. Wang, K. Schmidt, C. de Wit, J. Erdmann, H. Schunkert, Z. Aherrahrou, W. Kong, ADAMTS-7 inhibits re-endothelialization of injured arteries and promotes vascular remodeling through cleavage of thrombospondin-1, Circulation, 131 (2015) 1191-1201.

[24] S.D. Katugampola, Z. Pallikaros, A.P. Davenport, [125I-His(9)]-ghrelin, a novel radioligand for localizing GHS orphan receptors in human and rat tissue: up-regulation of receptors with athersclerosis, British journal of pharmacology, 134 (2001) 143-149.

[25] M.J. Kleinz, J.J. Maguire, J.N. Skepper, A.P. Davenport, Functional and immunocytochemical evidence for a role of ghrelin and des-octanoyl ghrelin in the regulation of vascular tone in man, Cardiovascular research, 69 (2006) 227-235.

[26] K.M. Habegger, E. Grant, P.T. Pfluger, D. Perez-Tilve, A. Daugherty, D. Bruemmer, M.H. Tschop, S.M. Hofmann, Ghrelin Receptor Deficiency does not Affect Diet-Induced Atherosclerosis in Low-Density Lipoprotein Receptor-Null Mice, Frontiers in endocrinology, 2 (2011) 67.

[27] M. Zhang, X. Qu, F. Yuan, Y. Yang, L. Xu, J. Dai, W. Wang, J. Fei, X. Hou, W. Fang, Ghrelin receptor deficiency aggravates atherosclerotic plaque instability and vascular inflammation, Frontiers in bioscience, 20 (2015) 604-613.

[28] W.G. Li, D. Gavrila, X. Liu, L. Wang, S. Gunnlaugsson, L.L. Stoll, M.L. McCormick, C.D. Sigmund, C. Tang, N.L. Weintraub, Ghrelin inhibits proinflammatory responses and nuclear factorkappaB activation in human endothelial cells, Circulation, 109 (2004) 2221-2226.

[29] C.Z. Hu, Y.L. Cao, H.Y. Huo, W.H. Zhao, J. Hu, Inhibitory effect of ghrelin on nicotine-induced VCAM-1 expression in human umbilical vein endothelial cells, Journal of cardiovascular pharmacology, 53 (2009) 241-245.

[30] E. Kellokoski, A. Kunnari, M. Jokela, S. Makela, Y.A. Kesaniemi, S. Horkko, Ghrelin and obestatin modulate early atherogenic processes on cells: enhancement of monocyte adhesion and oxidized low-density lipoprotein binding, Metabolism: clinical and experimental, 58 (2009) 15721580.

[31] E.Z. Sung, N.F. Da Silva, S.J. Goodyear, P.G. McTernan, R.P. Arasaradnam, C.U. Nwokolo, Ghrelin promotes nuclear factor kappa-B activation in a human B-lymphocyte cell line, Molecular biology reports, 38 (2011) 4833-4838.

[32] Z.Z. Liu, W.G. Wang, Q. Li, M. Tang, J. Li, W.T. Wu, Y.H. Wan, Z.G. Wang, S.S. Bao, J. Fei, Growth hormone secretagogue receptor is important in the development of experimental colitis, Cell \& bioscience, 5 (2015) 12.

[33] M. Zhan, F. Yuan, H. Liu, H. Chen, X. Qiu, W. Fang, Inhibition of proliferation and apoptosis of vascular smooth muscle cells by ghrelin, Acta biochimica et biophysica Sinica, 40 (2008) 769-776.

[34] D. Zhang, W. Wang, D. Zhou, Y. Chen, L. Han, Y. Liu, C. Cao, H. Zhao, G. Liu, Ghrelin inhibits apoptosis induced by palmitate in rat aortic endothelial cells, Medical science monitor : international medical journal of experimental and clinical research, 16 (2010) BR396-403. 
[35] M.S. Kim, C.Y. Yoon, P.G. Jang, Y.J. Park, C.S. Shin, H.S. Park, J.W. Ryu, Y.K. Pak, J.Y. Park, K.U. Lee, S.Y. Kim, H.K. Lee, Y.B. Kim, K.S. Park, The mitogenic and antiapoptotic actions of ghrelin in 3T3-L1 adipocytes, Molecular endocrinology, 18 (2004) 2291-2301.

[36] M. Gao, J. Yang, R. Wei, G. Liu, L. Zhang, H. Wang, G. Wang, H. Gao, G. Chen, T. Hong, Ghrelin induces cardiac lineage differentiation of human embryonic stem cells through ERK1/2 pathway, International journal of cardiology, 167 (2013) 2724-2733.

[37] M. Murata, Y. Okimura, K. Iida, M. Matsumoto, H. Sowa, H. Kaji, M. Kojima, K. Kangawa, K. Chihara, Ghrelin modulates the downstream molecules of insulin signaling in hepatoma cells, The Journal of biological chemistry, 277 (2002) 5667-5674. 


\section{Figure Legends}

Figure 1. GHSR deficiency inhibits neointimal formation after vascular injury. A, Cross sections of normal and injured femoral arteries from wild-type (WT) and GHSR ${ }^{-/}$mice evaluated by hematoxylin and eosin-staining at 14 days and 28 days after vascular injury. Neointimal hyperplasia is defined as the formation of the layer within the inner elastic lamina. B, Quantification of the neointimal area. C, Quantitative analysis of the luminal area. D, Quantification of the intima-to-media (I/M) ratio. E, Quantification of the medial area. $(n=7)$. $* \mathrm{P}<0.05$.

Figure 2. GHSR deficiency suppresses SMCs numbers in vivo. A, Immunohistochemical staining was performed on injured femoral arteries of WT and $\mathrm{GHSR}^{-/-}$mice to analyze the expression of $\alpha$-SMA, a molecular marker for SMCs and F4/80, a maker for macrophages. $\mathbf{B}$, The number of SMCs in neointima was calculated in WT mice and GHSR ${ }^{-/-}$mice. $(n=7) . \mathbf{C}$, SMCs proliferation rate was determined by BrdU-labeling assay. D, Quantitative analysis of BrdU labeling index of neointima. $(\mathrm{n}=5) .{ }^{*} \mathrm{P}<0.05$.

Figure 3. Knockdown GHSR Represses SMCs Proliferation and Migration in Vitro. A, SMCs were transfected with GHSR siRNA and scramble control. GHSR gene expression was analyzed with qRT-PCR. (n=3). B, Protein level of GHSR was detected by western blotting using antibody against GHSR after treatment with siRNA. C, The proliferation of SMCs were determined after stimulating with ghrelin (100nM, $24 \mathrm{~h}$ ) by Cell Counting Kit-8 (CCK8). ( $\mathrm{n}=6)$. D, Migration was measured with Transwell assay induced with PDGF-BB (5ng/mL, $24 \mathrm{~h})$ and observed by crystal violet staining. E, Quantitative analysis of cell numbers. $(\mathrm{n}=4)$. $* \mathrm{P}<0.05$.

Figure 4. Knockdown GHSR repressed ghrelin-induced Akt and ERK1/2 phosphorylation in cultured SMCs. SMCs transfected with siRNA were treated with ghrelin $(100 \mathrm{nM})$. The phosphorylation of Akt and ERK1/2 was analyzed by western blotting. p-Akt represents phosphorylated Akt; p-ERK1/2, phosphorylated ERK1/2. (n=3). 


\section{Figure 1}

A

Sham

Day 14

Day 28
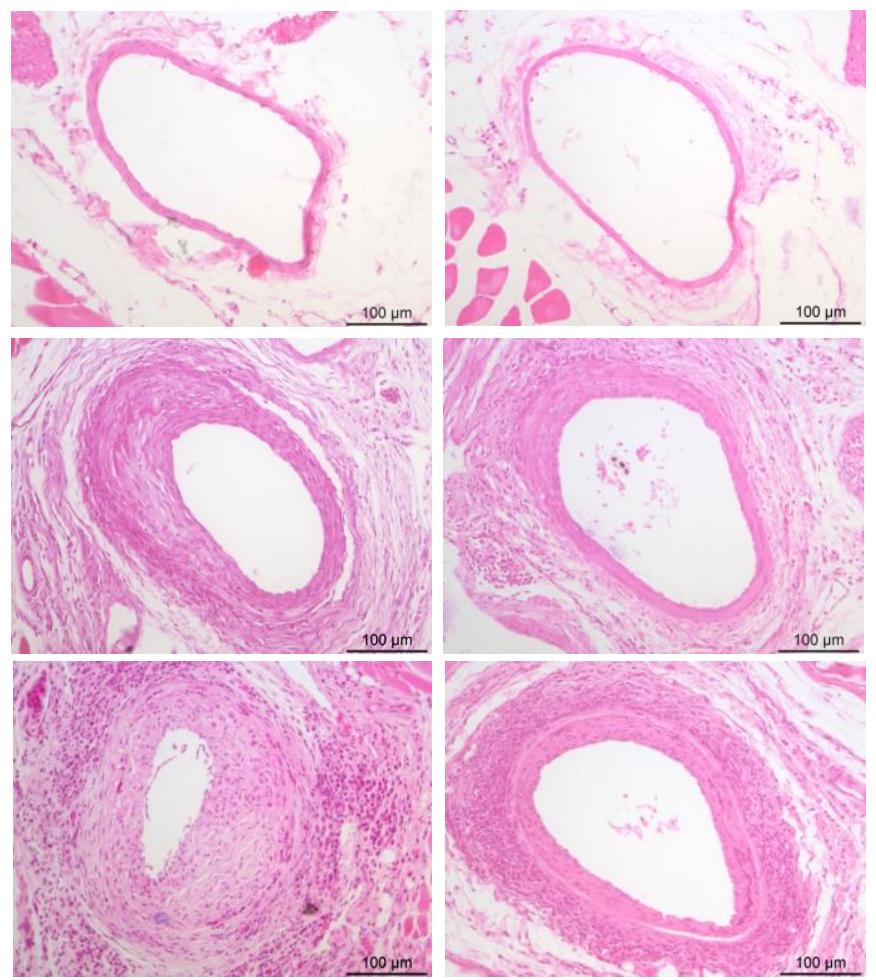

B

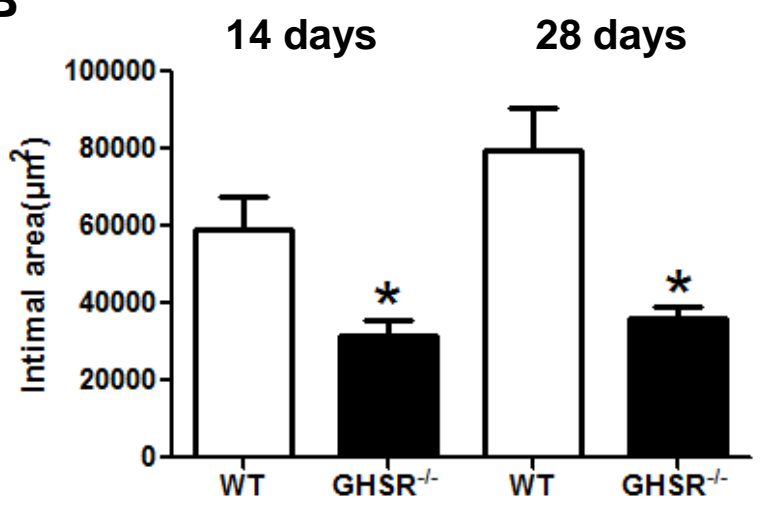

C

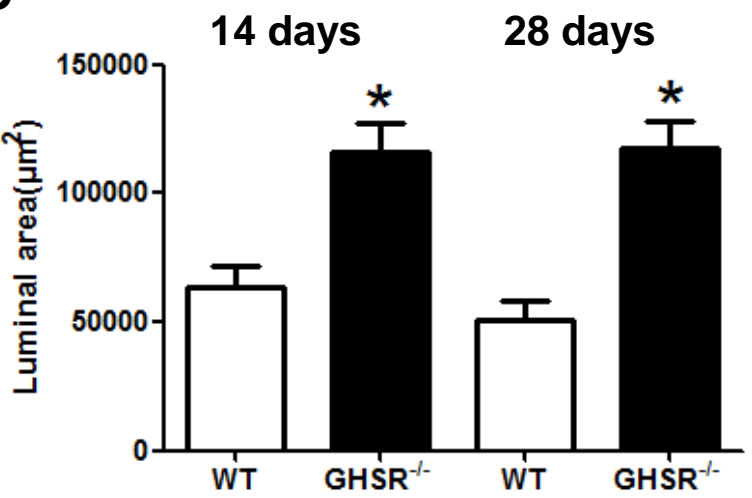

D

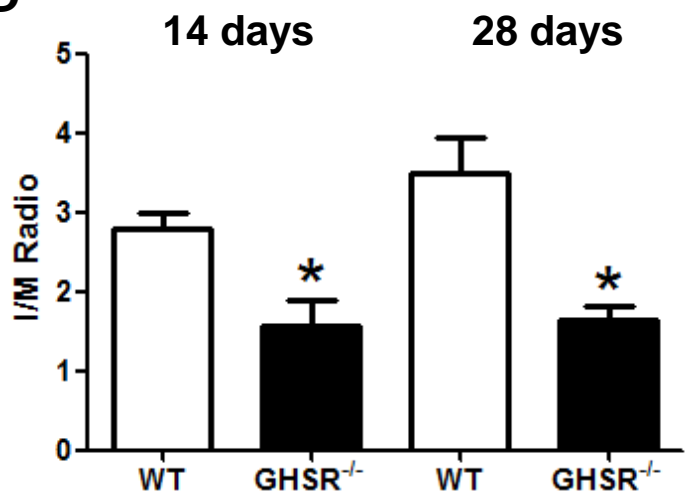

E

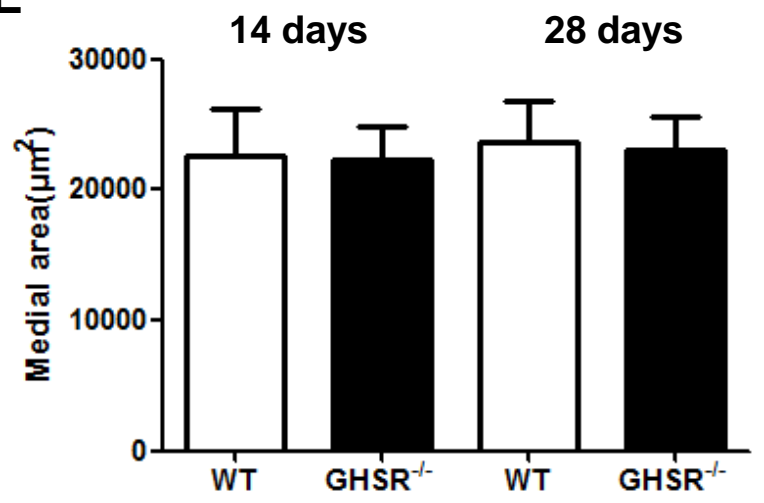


Figure 2

A
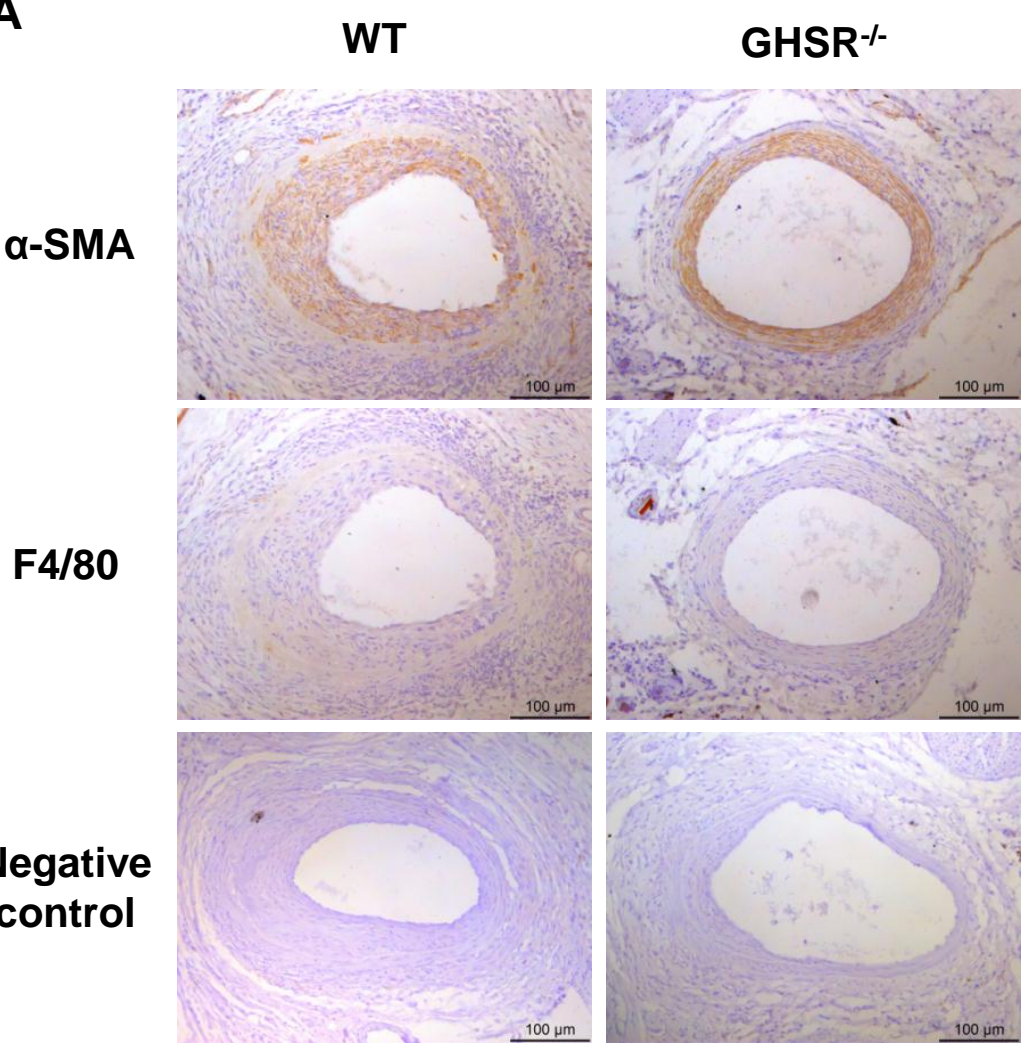

C
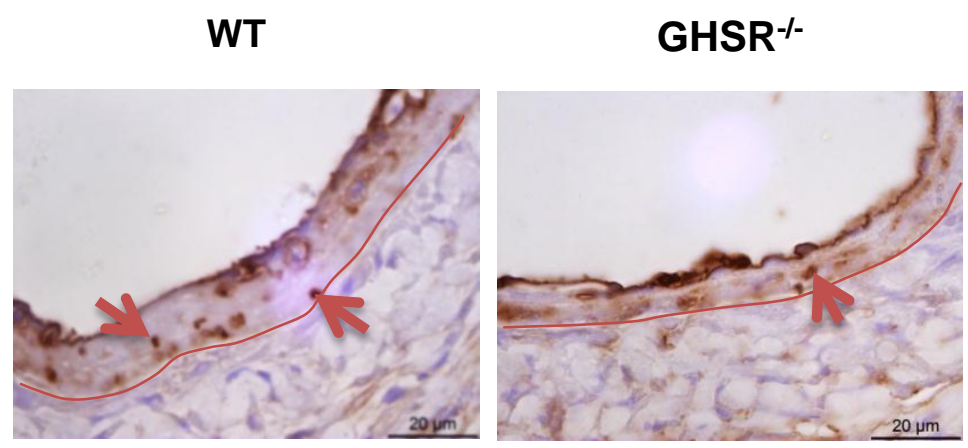

B

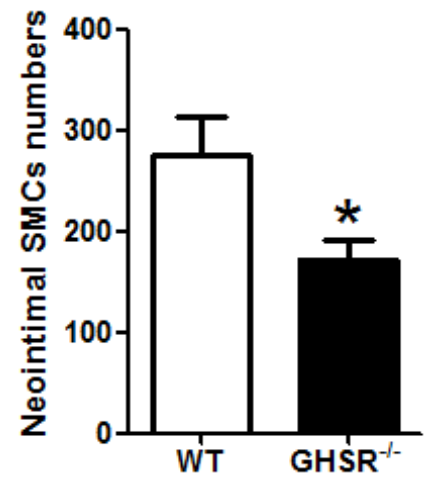

D

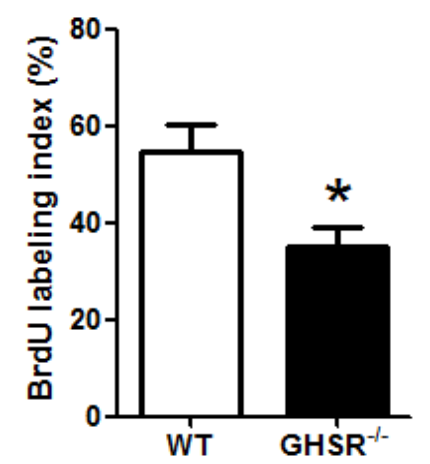


Figure 3

A

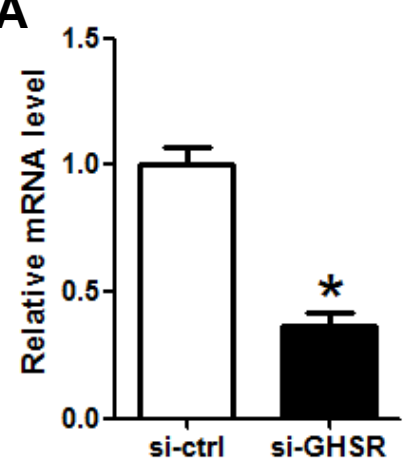

B

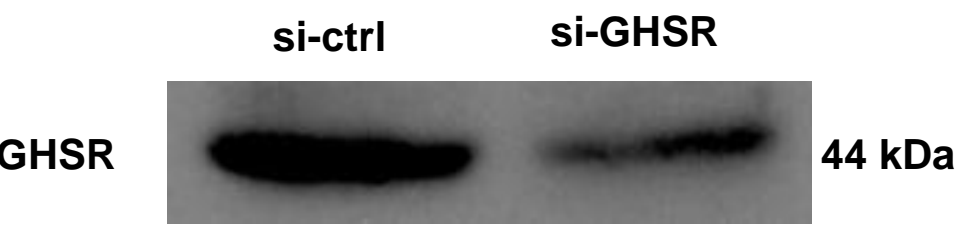

GAPDH

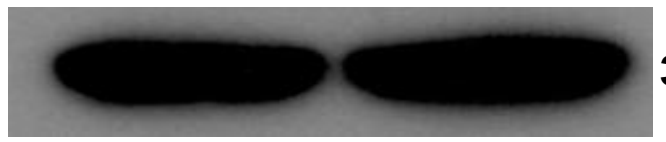

37 kDa

D

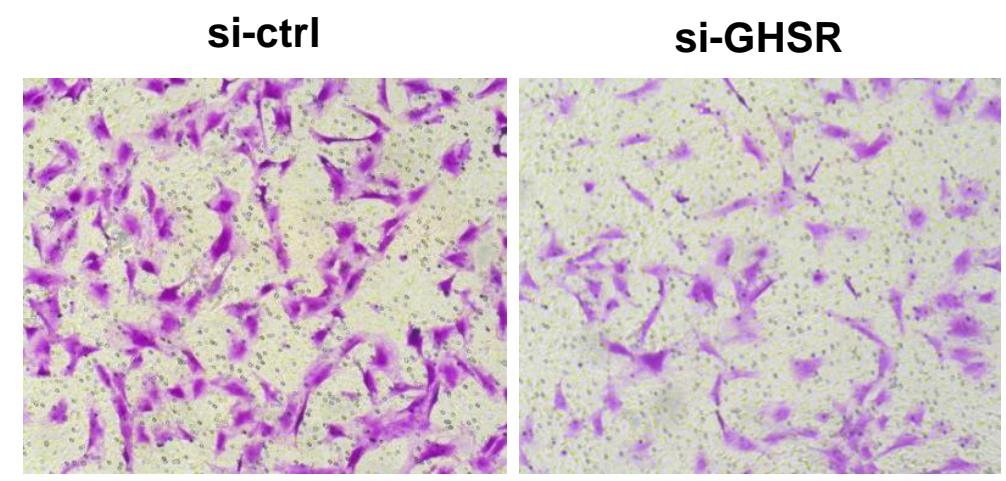

E

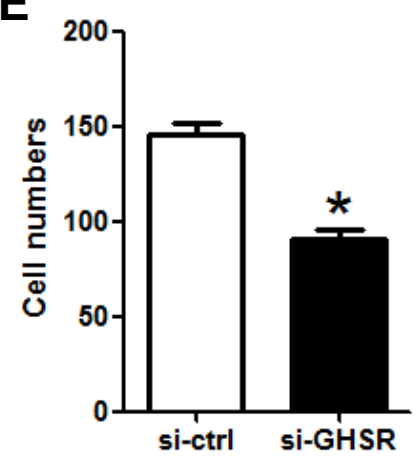


Figure 4

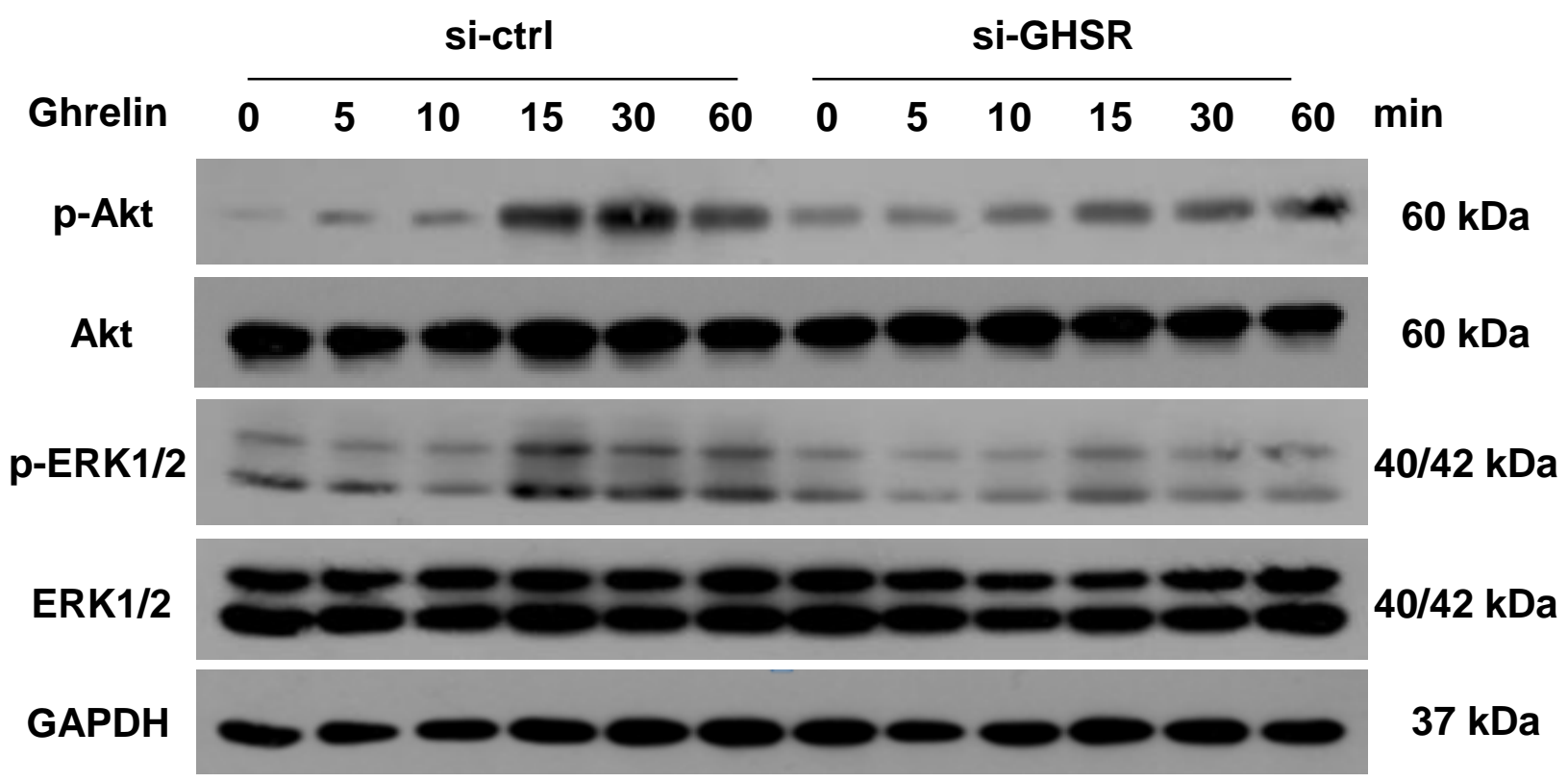

